\title{
Just a number? The impact of age on lung transplantation
}

\author{
Victor van Berkel, MD, PhD \\ From the Department of Cardiovascular and Thoracic Surgery, University of Louisville School of Medicine, \\ Louisville, Ky. \\ Disclosures: Author has nothing to disclose with regard to commercial support. \\ Received for publication Aug 6, 2017; accepted for publication Aug 18, 2017; available ahead of print Sept 26, \\ 2017. \\ Address for reprints: Victor van Berkel, MD, PhD, 201 Abraham Flexner Way, Suite 1200, Louisville, KY 40202 \\ (E-mail: victor.vanberkel@louisville.edu). \\ J Thorac Cardiovasc Surg 2017;154:2142-3 \\ $0022-5223 / \$ 36.00$ \\ Copyright $(\underset{2017}{ } 20 y$ The American Association for Thoracic Surgery \\ http://dx.doi.org/10.1016/j.jtcvs.2017.08.040
}

Historically, advanced age was considered an absolute contraindication to lung transplantation, for both physiologic and sociologic reasons. Early guidelines from the International Society for Heart and Lung Transplantation recommended transplants only for patients no older than 60 years. $^{1}$ As the patient population demographic has shifted towards older patients, and as the surgical fields have become more comfortable with performing complicated operations on elderly patients, ${ }^{2}$ these recommendations have evolved. After an initial change in 2006 listing age older than 65 years as a relative contraindication to transplantation, ${ }^{3}$ the most recent guidelines do not provide an upper limit for consideration of transplant candidacy. ${ }^{4}$

Support for this change in the guidelines has come from single-center studies demonstrating acceptable outcomes for transplant in elderly patients, ${ }^{5}$ although the larger registries continue to show a decrement in survival relative to younger patients. ${ }^{6}$ These differences suggest that individual centers may be identifying a subset of elderly patients who are better able to tolerate the transplant process.

In this issue of the Journal, Ehrsam and colleagues ${ }^{7}$ examine the transplant recipient population from the University of Zurich to identify factors that may contribute to worse survival among elderly patients. This is a retrospective analysis of 306 transplants performed during a 14year period at a single institution. They found that although their recipients older than 60 years did have a lower median survival, the mortality difference was no longer statistically significant once they controlled for comorbid variables. Several comorbidities were found to increase mortality; unsurprisingly, patients in the elderly population were more likely to have several of these comorbid conditions.

From a mathematical standpoint, demonstrating a loss of statistically significant difference between groups is not as rigorous as proving noninferiority of one group to another. There is a risk that the reason for a loss of significance is that the study is underpowered, and that a larger database of patients would still show worse outcomes in older patients, even after controlling for comorbidities. Unfortunately,

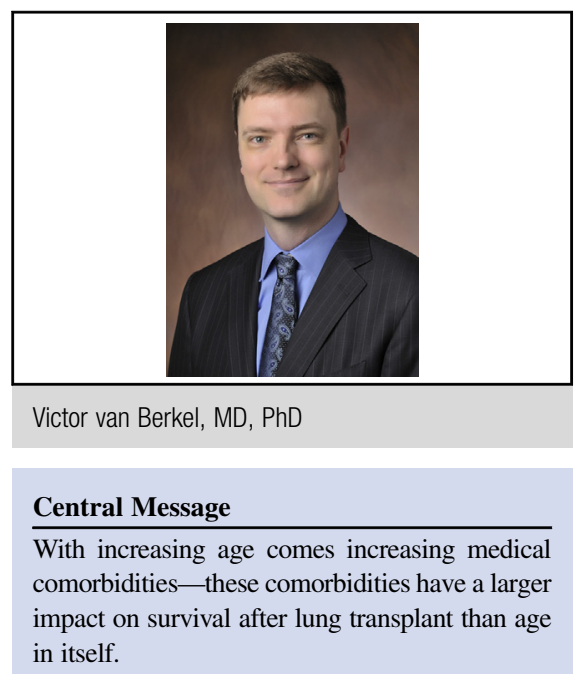

See Article page 2135.

the international databases do not currently have the granularity of data to assess this question completely.

With that caveat in mind, the findings of Ehrsam and colleagues ${ }^{7}$ reinforce the current guidelines, and the instincts of most transplant groups, by suggesting that age is not intrinsically detrimental to transplant. Older patients are simply more likely to have other medical comorbiditiesand these comorbidities are responsible for the decrease in survival. This suggests that if we select older recipients who are healthy apart from their pulmonary condition, we can expect comparable survivals to those of a younger population.

\section{References}

1. Maurer JR, Frost AE, Estenne M, Higenbottam T, Glanville AR, et al. International guidelines for the selection of lung transplant candidates. The International Society for Heart and Lung Transplantation, the American Thoracic Society, the American Society of Transplant Physicians, the European Respiratory Society. $J$ Heart Lung Transplant. 1998;17:703-9.

2. Goyal S, Henry M, Mohajeri M. Outcome and quality of life after cardiac surgery in octogenarians. ANZ J Surg. 2005;75:429-35.

3. Orens JB, Estenne M, Arcasoy S, Conte JV, Corris P, Egan JJ, et al. Pulmonary Scientific Council of the International Society for Heart and Lung Transplantation. International guidelines for the selection of lung transplant candidates: 2006 update- a consensus report from the Pulmonary Scientific Council of the International Society for Heart and Lung Transplantation. J Heart Lung Transplant. 2006;25:745-55.

4. Weill D, Benden C, Corris PA, Dark JH, Davis RD, Keshavjee S, et al. A consensus document for the selection of lung transplant candidates: 2014 — an update from the Pulmonary Transplantation Council of the International Society for Heart and Lung Transplantation. J Heart Lung Transplant. 2015;34:1-15.

5. Tomaszek SC, Fibla JJ, Dierkhising RA, Scott JP, Shen KR, Wigle DA, et al. Outcome of lung transplantation in elderly recipients. Eur J Cardiothorac Surg. 2011;39:726-31

6. Yusen RD, Edwards LB, Dipchand AI, Goldfarb SB, Kucheryavaya AY, Levvey BJ, et al. International Society for Heart and Lung Transplantation. The 
Registry of the International Society for Heart and Lung Transplantation: thirty-third adult lung and heart-lung transplant report-2016; focus theme: primary diagnostic indications for transplant. J Heart Lung Transplant. 2016; $35: 1170-84$.
7. Ehrsam JP, Benden C, Seifert B, Opitz I, Schneiter D, Weder W, et al Lung transplantation in the elderly: influence of age, comorbidities, underlying disease, and extended criteria donor lungs. J Thorac Cardiovasc Surg. 2017; $154: 2135-41$. 